Tjalling C. Koopmans Research Institute

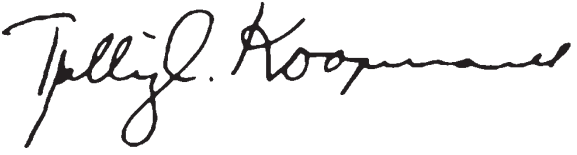

Discussion Paper Series nr: 07-13

\title{
The Welfare Optimal Distribution of Olympic Success Considered as a Public Good
}

Loek Groot 


\section{Tjalling C. Koopmans Research Institute Utrecht School of Economics \\ Utrecht University}

Janskerkhof 12

3512 BL Utrecht

The Netherlands

telephone +31302539800

fax $\quad+31302537373$

website www.koopmansinstitute.uu.nl

The Tjalling C. Koopmans Institute is the research institute and research school of Utrecht School of Economics.

It was founded in 2003, and named after Professor Tjalling C. Koopmans, Dutch-born Nobel Prize laureate in economics of 1975.

In the discussion papers series the Koopmans Institute publishes results of ongoing research for early dissemination of research results, and to enhance discussion with colleagues.

Please send any comments and suggestions on the Koopmans institute, or this series to s.mook@econ.uu.nl

ontwerp voorblad: WRIK Utrecht

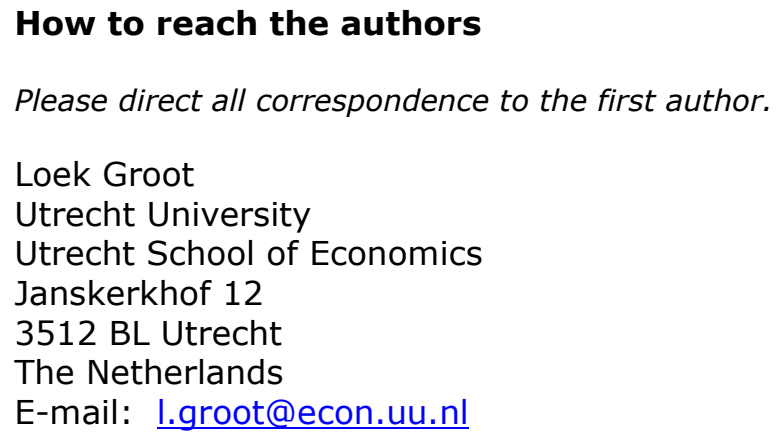

Please direct all correspondence to the first author.

Loek Groot

Utrecht University

Utrecht School of Economics

Janskerkhof 12

3512 BL Utrecht

The Netherlands

E-mail: l.groot@econ.uu.nl

This paper can be downloaded at: http://www.koopmansinstitute.uu.nl 
Utrecht School of Economics

Tjalling C. Koopmans Research Institute

Discussion Paper Series 07-13

\title{
The Welfare Optimal Distribution of Olympic Success Considered as a Public Good
}

\author{
Loek Groota \\ aUtrecht School of Economics \\ Utrecht University
}

March 2007

\begin{abstract}
This study considers the performance of countries at the Olympic Games as a public good and investigates different welfare optimal distributions of Olympic success. First, it is argued that at the national level Olympic success, measured as the number of gold medals won, meets the two key conditions of a public good, nonrivalry and non-excludability. Second, it is demonstrated that standard income inequality measures as the Lorenz curve and Atkinson's measure can successfully be applied to the distribution of Olympic success. Four different distributions are considered: the actual distribution, the distribution according to population shares, the distribution under constant and declining marginal utility of medals and the one also taking production costs and declining marginal utility of per capita income into account. For the latter two, the rules for the welfare optimal distributions are stated, viz. equality of the marginal contributions to welfare and the Samuelson condition. At the end, a device is proposed to make the distribution of Olympic success more equitable.
\end{abstract}

Keywords: Olympic Games, Public Goods, Externalities, Social Welfare

JEL classification: D63, H41, H50 


\section{Introduction}

At the Summer Olympics Games 2004 in Athens, more than 11 thousand athletes from over 200 countries competed for medals in 301 different disciplines. In total 929 Medals were distributed. ${ }^{1}$ Overall, more than half (56\%) of all medals, and $60 \%$ of all gold medals, were collected by the Top 10 countries which only comprise one third of the world population. ${ }^{2} 63 \%$ of the participating countries did not get any medal, and only one out of four participating countries succeeded in winning at least one golden medal.

At face value, these figures do not show that the medal tally is (un)equally distributed over countries. Whether or not the medal tally is (un)evenly distributed depends on the criteria used. With a few exceptions, the economic literature on Olympic performance concentrates on explaining the performance of countries at the Olympic games by identifying relevant factors like population size, GDP and GDP per capita, hosting and neighbouring countries and socialist background. By and large, the explanatory power of these models is quite high. For example, Bernard and Busse (2004: 417) deploy their favourite model $^{3}$ to an out-of-sample prediction for the

\footnotetext{
${ }^{1}$ The total medal count is more than three times the number of disciplines, because sometimes medalwinning athletes end exactly equal, in which case a double bronze, silver of golden medal is awarded.

${ }^{2}$ Exclusion of China from the top 10 gives that the other 9 countries, with a world population share of only $14 \%$, capture half of all gold medals. For the Olympics 2000, the top ten had a gold share of $66 \%$ against a population share of 33\%. In 1996 it was 65\% against 34\%, in $199278 \%$ against 34\%, in 1988 $81 \%$ against $14 \%$.

${ }^{3}$ Apart from the specific econometric techniques, the main difference of the model of Bernard and Busse from other conventional models explaining the medal tally (e.g. Bian (2005), Hoffmann et al. (2002; 2004) and Tcha (2004)) is the inclusion of a variable representing the lagged medal share. This variable stands for the 'time to build'-effect: investments for one Olympics increases the winning odds in subsequent Olympic Games. Past success turns out to be a strong predictor of current success,
} 
medal tally of the Summer Olympics of 1996 and attain an $\mathrm{R}^{2}$ of $96 \%$. Johnson and Ali (2004: 982-8) attain similar figures for the out-of-sample predictions for the number of participants and the gold medal count per country at the Winter Olympics in Salt Lake City $2002\left(\mathrm{R}^{2}=0.96\right.$ and 0.85 respectively) and at the Summer Olympics 2000 in Sydney $\left(\mathrm{R}^{2}=0.95\right.$ and 0.85 respectively). There is not much to improve here. However, what is now most challenging is to explain which countries will win which medals. Tscha and Pershin (2003) started this project by applying the analysis of comparative advantages in international trade theory to the country's performances in each sport. In contrast to this strand of research, the purpose of this paper is not to explain which factors determine the distribution of Olympic medals, but how it should ideally be distributed. Instead of taking an explanatory or descriptive perspective, I deliberately adopt a normative perspective. There are several reasons why a normative perspective may be interesting.

First of all, the distribution of Olympic medals is a zero sum game. By definition, the number of different disciplines is limited and fixed ex ante, and per discipline or event only three medals can be assigned. Therefore, any country trying or succeeding in getting a larger share in the medal count imposes a negative externality on all other competing countries. From a normative perspective, it can be desirable to change the incentives in such a way that relatively (un)successful countries become (more) less successful. I will give an example of one such instrument, the auction of entry tickets, in section 5.

Secondly, the former socialist countries have shown that, in a sense, Olympic success (herafter abbreviated as OS) can be manufactured. At the last issue just before the fall of the Wall in 1989, the Olympic Summer Games of Seoul 1988, the People's indicating that (investments in) OS can be seen as a kind of durable capital good bearing fruit over several Olympic cycles. 
Republic of Germany DDR with only 17 million inhabitants won more gold medals than the USA with a population of nearly 250 million. More than $55 \%$ of all gold medals went to the socialist countries. Five formerly socialist countries (USSR, DDR, Hungary, Bulgaria and Romania) were in the top 10 , together comprising only $4.1 \%$ of the world population, but winning nearly half of all gold medals. Although doping may have played a role in this extreme score, for sure these countries have shown that a purposive sport policy can breed OS. After the demise of most of the socialist countries in 1989, and in its wake also their superior international sport performance, it becomes more and more attractive for other countries all over the world to pursue a purposive policy of their own to share as much in the OS. To an increasing extent, countries embark in a rat race to compete for OS by means of government expenditures exclusively allocated to stimulate top sport, whereas these scarce resources could also be allocated to sport activities in general. From a normative perspective, it might be preferable to allocate more of the national sport budget to promote amateur sport, instead of the high expenditures allocated on top sport. ${ }^{4}$

Thirdly, as in trade, some countries have comparative advantages in some sports. One of the best examples is Kenya, with a population of only 28 million, but the world leader of distance running. Barra (Wall Street Journal, 20 September 2000) argues that 'based on population percentages alone, the odds of Kenya dominating these events would be one in 1.6 billion'. 5 If it is indeed the case that countries have comparative advantages in some sports, e.g. due to the genetic endowments of their population, then it is efficient that they specialize in these sports and not in others.

\footnotetext{
${ }^{4}$ For instance, The Netherlands spend about $€ 80$ million, a quarter of the entire governmental sport budget, for the present Olympic cycle up to Beijing 2008 to realize its ambition of a place among the top 10 .

${ }^{5}$ A better example still is the inhabitants of the Nandi district in Kenya, with 500 thousand people holding about $20 \%$ of the world distant records in running in 2000.
} 
Specialization is more optimal than when (too) many countries compete for success in the same discipline. Matros and Namoro (2004: 5) suggest that in the past, based on the observation that the USA, USSR and DDR share the podium much less than could be expected based on their overall performance, they strategically and tacitly splitted the market for medals.

Fourthly, the celebration of OS is essentially a public good, because the pleasure spurred by an athlete winning gold is truly a non-excludable and non-rival good. The enjoyment of one passive spectator seeing his fellow countryman win a medal is not rival with the enjoyment of another spectator from the same country: one's consumption does not reduce the consumption of others and all can consume OS at the level of its total supply. Nor is it possible to exclude some citizens from passively sharing in the success of its country. Therefore, the passive enjoyment of OS meets the two key conditions of a pure public good. Since it is non-excludable, private markets may not generate the optimal amount of OS. As far as I know, the public good nature of OS, because of the non-exclusion and non-rivalry attributes, is never addressed in the economic literature. ${ }^{6}$ As with other public goods, there is a prima facie case for the government to intervene in the provision of this good. ${ }^{7}$

However, there are also good reasons to evaluate the premise of this study, to arrive at a distribution of OS which is more just or resulting in higher social welfare, as highly questionable. First of all, the purpose of the Games is to single out the winners, i.e. the best must win, irrespective whether the overall distribution of OS is

\footnotetext{
${ }^{6}$ Moosa and Smith (2004: 288) refer to the Coe report of 1985, where arguments are given why governments care about OS and why OS resembles a public good: "First, success makes people proud of their national identity and vice versa. Second, success in the Olympics improves the country's image abroad, helping to sell national products. Third, it boosts participation in sport and recreation, leading to a general improvements in the health of the average citizen." These three arguments do not refer to non-excludability or non-rivalry.

${ }^{7}$ This might explain why many countries do have tax-funded top sport policies.
} 
in (dis)agreement with some kind of pattern based on justice or social welfare. Second, there are huge differences between countries, not only in genetic endowments of its population and natural environment, but also in culture. These differences influences each country's chances on OS, but also imping on the value attached to OS. Maybe successful countries care more about OS than relatively unsuccessful countries. If so, then a social welfare function should take these differences into account. Admittedly, taking these and other objections to apply social welfare functions to sport contests seriously would make the analysis in this paper a nonstarter. In what follows it is heuristically assumed that $(i)$ the Olympic Games are really global in the sense that citizens in all countries have identical utility functions for OS and (ii) that the distribution of OS is not a kind of natural distribution, but to a considerable extent already manufactured by top sport policies adopted by national governments and international governing bodies.

\section{The actual versus the default just distribution of Olympic success}

In this and the following sections, we concentrate on the distribution of gold medals. In Table 1, the countries are ranked in descending order according to population shares (column 2). Column 3 gives the actual gold medal tally of Athens 2004, and column 4 the gold medal share. If gold medals were distributed proportional to population shares (see column 5), then China should receive twice as much as its actual share now, India should win 50 gold medals, while the USA only retains 14 gold medals. Column 6 gives the difference between the actual medal share and the proportional medal share. As can be seen from column 6, it is mainly the rich countries (USA, Germany, UK, France, Italy and Japan) which capture a much larger 
share of medals than would follow if medals were distributed according to population shares. ${ }^{8}$ These six rich countries comprise only $10.7 \%$ of the world population, but capture almost three out of ten of all gold medals (31.6\%), so an 'excessive share' of $20.9 \%$. Due to the zero sum game of Olympic medals, the higher than proportional share of some countries has as mirror image that other countries receive less than their proportional share. Populous India (with no gold and only a silver medal in 2004) and China together more than compensate $(26.9 \% / 20.9 \%)$ the higher than proportional share of gold of these six countries.

\footnotetext{
${ }^{8}$ A notable exception is Russia, which even has the highest ratio of medal share and population share of the countries listed in Table 1.
} 
Table 1. Four different distributions of Olympic success.

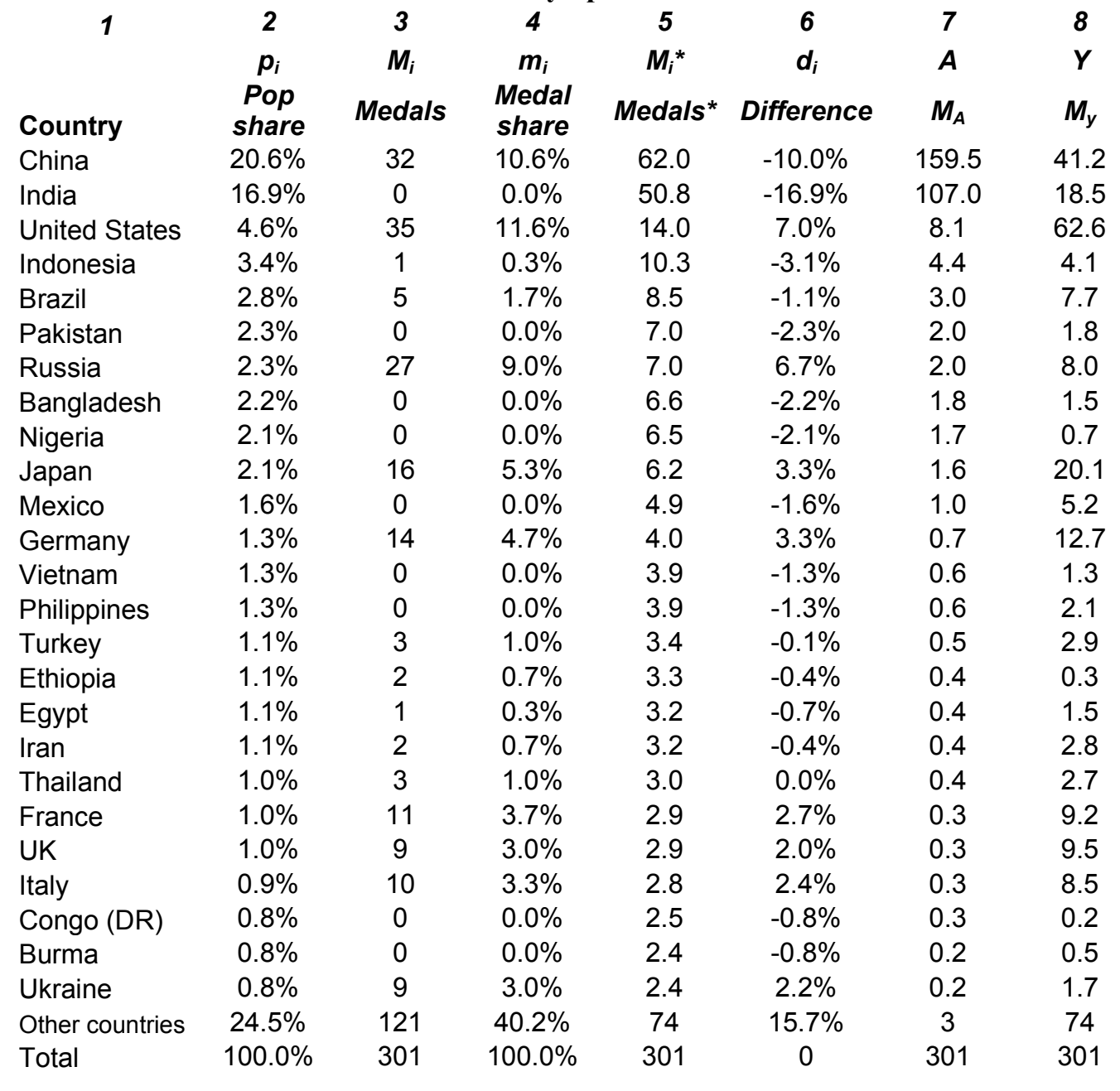

Both distributions can be nicely illustrated by means of the Lorenz curve (see Figures $1 \mathrm{~A}$ and $1 \mathrm{~B})$, with the cumulative population share on the horizontal axis and the cumulative medal share on the vertical axis. There are two ways to rank countries. In Figure $1 \mathrm{~A}$ countries are sorted in ascending order according to the number of gold medals won, whereas in Figure 1B they are sorted according to the ratio of their medal share and population share (see columns 2 and 4 of Table 1). To illustrate the difference, consider China. It has a medal score of 32 , and is therefore situated at the 
top right corner of the Lorenz curve in Figure 1A, with only the USA at its right. ${ }^{9}$ Figure 1A is strictly parallel to the Lorenz curve applied to income inequality (here inequality in medal scores), where China is considered as a rich country, and most in line with treating OS as a public good. In Figure 1B, China is situated far more to the left, because its ratio of medal share and population share is only 0.5 . Figure $1 \mathrm{~B}$ is more relevant to illustrate the inequality in OS relative to population shares of different countries. Both Lorenz curves have a fat belly, indicating a very unequal distribution of OS. In the subsequent discussion, I will concentrate on Figure 1B, as this is the one most relevant for later sections in this paper.

\section{Panel A}

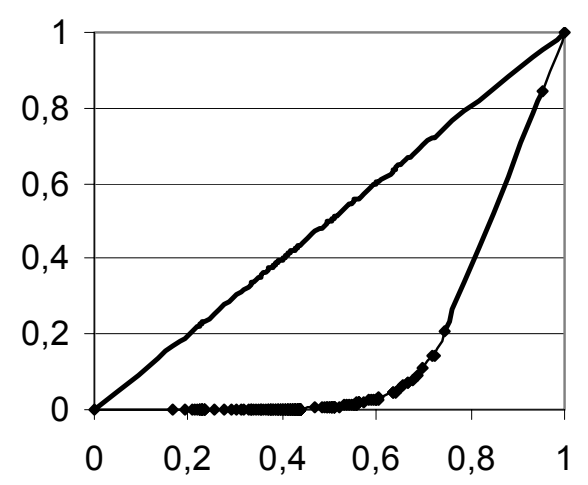

\footnotetext{
${ }^{9}$ In drawing the Lorenz curve of Figure 1A, for each country the product of the medal score and world population share is calculated, which is used to obtain the cumulative fractions, which adds up to a population weighted average medal score of 10.4 .
} 


\section{Panel B}

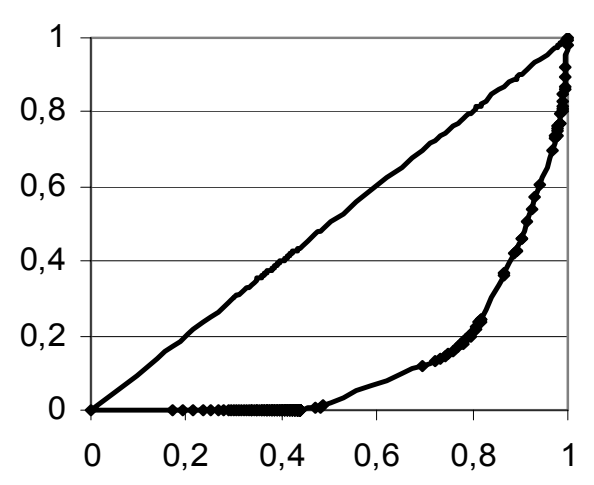

Figure 1. The Lorenz curves applied to the distribution of Olympic gold medals Panel A: Countries sorted by the number of gold medals Panel B: Countries sorted by the ratio of medal and population shares

These Lorenz curves show that almost half of the world population has a zero medal share, and $80 \%$ of the world population only has a medal share of $20 \%$. At the left side in Figure 1B, as long as the slope of the curve is less than the slope of the diagonal (which has a slope of 1), are all countries which have a lower than proportional medal score. These are the countries that have a negative value for the difference (column 6 in Table 1) between the actual medal score and the medal score proportional to their population share (alternatively, these are the countries for which the ratio between the medal share and population share is less than 1). On this segment, besides all countries without any medals, India and China are located. Predominantly, these countries are Second or Third World countries (with the exception of Hong Kong, Finland and Slovenia, with no gold medals). Turkey (with a ratio of 0.88 ) is the country situated most nearly left to the kink in the curve. To the right of the kink, the slope of the curve is higher than of the diagonal, and on this segment the countries are located with higher than proportional medal scores. On this segment we find first Thailand (with a ratio slightly above unity) and ending with 
Norway (a ratio of 23) and the Bahamas (a ratio of 66). In between, all the rich countries are represented, along with countries with a strong sport culture (Russia and former socialist countries) or definite comparative advantages in particular sports (notably some African countries). The further the curve will lie from the diagonal, the greater the degree of disproportional medals shares compared to population shares. ${ }^{10}$ The proportional distribution represented by the $45^{\circ}$ line can be considered as the default just distribution: every world citizen has then the same chance of success, irrespective of political regime, income per capita, race or religion. However, both distributions are not necessarily welfare optimal, where welfare optimal is taken to be the distribution that maximizes world welfare.

\section{The welfare optimal distribution of Olympic success with constant or declining marginal utility of medals}

Without government support, the aggregate marginal social benefits of OS may be much higher than the marginal social cost of medal production, indicating an undersupply of medals at the national level. For each country separately, the optimal level of OS is where the sum of marginal social benefits for the whole population is equal to the marginal social cost of manufacturing Olympic medals (see section 4). In this section, I will abstract from production costs and show stepwise that the optimal

\footnotetext{
${ }^{10}$ The degree of inequality depicted by the Lorenz curve can be expressed at the Gini coefficient. The Gini coefficient is graphically the ratio of the area in between the diagonal and the curve and the triangle below the diagonal.
} 
distribution is the one where the marginal contributions to welfare are equalized across countries.

In welfare theory, total welfare is measured by summing up welfare over individuals. Every individual counts as one, - and why should an African farmer count different than an American attorney? - and because OS can be considered as a public good, the total welfare from winning medals at the Olympics is a function of the utility that individuals all over the world experience when fellow country(wo)men win a medal, weighted by the largesse of the populations (see Eq. 1). The population shares are given, the utility function still need to be specified.

(1) $W=\frac{1}{N} \sum_{i=1}^{n} P_{i} U_{i}$

with

$W=$ world welfare;

$U_{i}=$ utility per capita in country $i$

$N=$ total world population; ${ }^{11}$

$P_{\mathrm{i}}=$ population in country $i$;

$n=$ number of countries.

\subsection{Constant marginal utility of OS}

If there is no decreasing marginal utility in medals won, then:

(2) $U_{i}=M_{i}$

\footnotetext{
${ }^{11}$ The total world population in 2004 was about 6.3 billion (population data are available at http://www.eia.doe.gov/pub/international/iealf/tableb1.xls).
} 
with

$M_{\mathrm{i}}=$ number of medals for country $i$.

Equation (2) expresses that individual utility in a country $i$ is proportional to the number of medals won. Throughout the paper I will assume that people obtain utility only if their compatriots win medals. ${ }^{12}$ This implies that they do not experience any (dis)utility if anyone else than their fellow country(wo)men win medals. For simplicity, assume that all disciplines are equally important (so, a gold medal in obscure sports as fence, archery or skeet shooting is as important as one in track and field). Defining $p_{\mathrm{i}} \equiv P_{\mathrm{i}} / N$ as each country's world population share and substituting (1) into (2) gives:

(3) $W=\sum_{i=1}^{n} p_{i} M_{i}$, so under constant marginal utility the welfare is equal to the population share weighted average medal score. In Table $1, p_{\mathrm{i}}$ is given in column (2) and $M_{\mathrm{i}}$ in column (3). Total actual welfare $W^{13}$ is the sum of the product of population share and medal count and equal to 10.4. Under these assumptions, obviously the optimal distribution of medals is the one where all medals are concentrated among the most populous country China. This gives a welfare and average medal score of $0.206 * 301=62$. Of course, China capturing all medals is a far cry from what was labelled as the default

\footnotetext{
${ }^{12}$ I take for granted that this may be interpreted as a male, nationalistic or chauvinist stance. A true sport fan would derive maximum utility when the best win, whatever their country of origin. In that case, the distribution of medals across countries is of no concern at all.

${ }^{13}$ In Table 1 countries are ranked according to population shares. Besides the 25 countries listed, there were 50 other medal winning countries, all with population shares below 1\%, which together won 121 gold medals. The sum of their contribution to welfare is each country gold medal score times their population share. Summed up over all 50 countries, their contribution is only 0.4.
} 
just distribution, the one exactly proportional to population shares (see column 5, Table 1). Total welfare under the proportional distribution is approximately equal to 23.7, more than twice the level of actual welfare. This outcome duly illustrates the strong assumptions of the whole analysis: that medals are considered as a public good, that they can be (re)distributed and that social welfare of OS has some specific function.

\subsection{Decreasing marginal utility of Olympic success}

To go one step further, we have to take into account that it is realistic to assume that on average the enjoyment per medal decreases when the medal score of the country increases. A commonly used index to take aboard the declining marginal utility is the Atkinson inequality measure, which can be expressed in this context as:

(4) $W=\sum_{i=1}^{n} p_{i} U_{i}\left(M_{i}\right)$

with

(5) $U_{i}\left(M_{i} ; \varepsilon\right)=\frac{1}{1-\varepsilon} M_{i}^{1-\varepsilon} \quad \varepsilon \neq 1$, if $\varepsilon=1, U_{i}\left(M_{i}\right)=\log \left(M_{i}\right)$

If $\varepsilon=0$, then welfare is measured by the arithmetic mean medal score, given by Eq. (3). If all countries were equally populous, then under $\varepsilon=0$ the distribution of medals would be irrelevant. For $\varepsilon>0$ however, there is a trade-off. On the one hand, more medals should be allocated to the more populated countries. On the other hand, because $\varepsilon>0$ there is a declining marginal utility of medals. Therefore, it is not 
optimal to allocate all medals to the most populated country, or strictly proportional to population shares.

Related to Atkinson's measure is the concept of the equally distributed equivalent income (in this case medals). It can be defined here as the equalized medal score, call this $M_{e}$, which generates the same level of welfare as the actual distribution. Hence, using (4) and (5), $M_{e}$ can be defined by:

(6) $W=\sum_{i=1}^{n} p_{i} U_{i}\left(M_{i}\right)=\sum_{i=1}^{n} p_{i} \frac{1}{1-\varepsilon} M_{i}^{1-\varepsilon}=U\left(M_{e}\right)=\frac{1}{1-\varepsilon} M_{e}^{1-\varepsilon}$

It can be easily calculated that for $\varepsilon=0, M_{e}=\bar{M}=10.4$. For $\varepsilon=0.5, W=4.3$, so $M_{e}=$ 4.6. ${ }^{14}$ Using $M_{e}$ and $\bar{M}$, Atkinson's inequality measure can be calculated as the proportional difference between the arithmetic mean medal score $\bar{M}$ and the equally distributed equivalent medal score $M_{e}$ :

(7) $A(\varepsilon)=1-M_{e} / \bar{M}$

By definition, $A(0)=0$ and $A(\infty) \rightarrow 1$. For $\varepsilon=0.5, A(0.5)=0.55 .^{15}$ The meaning of $\varepsilon$ is linked to what has become known as Okun's leaky bucket. Consider taxing \$1 from a rich person and transferring $\$ x$ to a poor person, so $\$ 1-x$ is lost due to disincentives

\footnotetext{
${ }^{14}$ If $\varepsilon \rightarrow \infty$, the maximum welfare is only determined by the position of the country with the lowest medal score. Given that the number of disciplines (301) is roughly $50 \%$ higher than the number of countries in the world (202), this would imply an impeccable equal distribution (e.g. one and a half gold medal, or for some countries two gold medals and for others some combination of one gold and more silver and bronze to compensate) of all medals across all countries, no matter how rich or populous, is the optimal outcome.

${ }^{15}$ Other values for $\varepsilon$ could be chosen. The choice of $\varepsilon=0.5$ has the advantage that it both reflects declining marginal utility and is easy to interpret, namely utility is just the square root of the medal score.
} 
and administration costs. The value of $\varepsilon$ follows from answering the question 'How far can $x$ fall before we evaluate this tax-and-transfer operation no longer desirable?'. This property of the Atkinson measure can nicely be illustrated by means of an example of two equally populous contries, say Brazil and Russia. At the 2004 Olympic Games, Brazil got 5 gold medals and Russia 27. Figure 2 gives the social welfare functions for $\varepsilon=0$ (the straight line), $\varepsilon=0.5, \varepsilon=1$ and $\varepsilon=2$. The higher the value of $\varepsilon$, the more utility declines with the number of medals, the greater the curve of the social welfare function. For each value of $\varepsilon$, the equally distributed equivalent medal score $M_{e}$ can be calculated from:

(8) $M_{e}=\left(1 / 2 \sum_{i=1}^{2} M_{i}^{1-\varepsilon}\right)^{1 / 1-\varepsilon}$

For $\varepsilon=0, M_{e}=\bar{M}=16$, for $\varepsilon=0.5, M_{e}=13.8$, for $\varepsilon=1, M_{e}=11.6$ and for $\varepsilon=2, M_{e}=$ 8.4. The higher the value of $\varepsilon$, the less medals are required to reach the same level of welfare by redistributing medals from the more successful country to the unsuccessful country. Using Eq. (7), it can easily be calculated that $A(0)=0, A(0.5)=0137, A(1)=$ 0.274 and $A(2)=0.475$. Using these numbers, the leacky bucket can now be stated in the following way: to reach the same level of social welfare, only the fraction of 1$A(\varepsilon)$ of total medals is required if these are equally distributed. Since for a given distribution, $A(\varepsilon)$ is higher, the higher the value of $\varepsilon$, it follows that for higher values of $\varepsilon$ a more leaky bucket is tolerable. For example, if $\varepsilon=2$, we need only $1-0.475=$ 0.525 of all 32 medals, so 16.8 divided equally over both countries, to reach the same level of social welfare as the actual distribution of 27 to Russia and 5 to Brazil. 


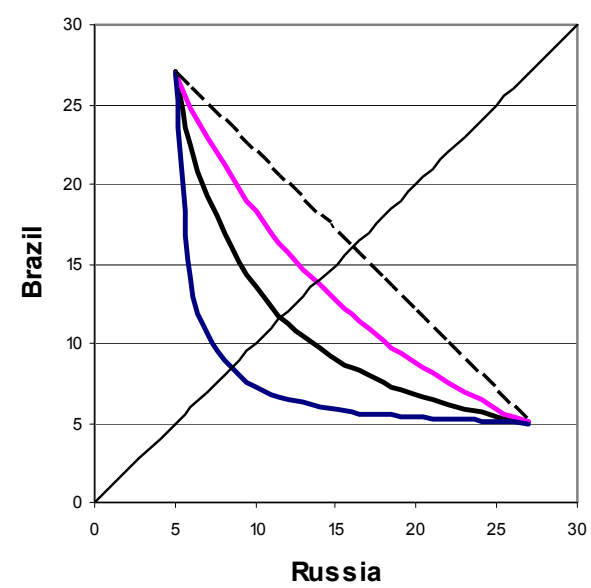

Figure 2. Social welfare functions for different values of the risk aversion parameter $\varepsilon$ in a two country case

Now, for two reasons there is no strict parallel to the leaky bucket of the income (re)distribution to the Olympic games. Firstly, because the distribution of Olympic medals is a zero sum game, every medal 'taken' from the more successful countries will be fully captured by other countries, so these transfers go without any losses in the total number of medals to be distributed. However, and secondly, because OS is contrary to income a public good, it matters a lot whether a medal is redistributed from a country with a large population to one with a small population or the other way around. Suppose the Bahamas holds one gold medal and India none. A transfer of this medal from the Bahamas to India will result in an enormous welfare increase, although the total number of medals remains unchanged. ${ }^{16}$

To find the optimal distribution of medals, we have to equalize the marginal contribution to welfare for each country:

\footnotetext{
${ }^{16}$ In the domain of incomes, if the population density of the poor is $y$-times that of the rich class, then at best only $\$ 1 / y$ can be tranferred to each person in the poor class per $\$$ tax revenue collected from the rich. With OS, a one-to-one transfer is possible, whatever the divergence in population shares.
} 
(9) $\frac{\partial W}{\partial M_{i}}=\frac{\partial W}{\partial M_{j}}$

Equation (9) is the rule that governs the optimal distribution of medals, ${ }^{17}$ abstracting from the cost and production of medals (see the next section). Because the population shares are given, using Eqs. (4) and (5), the derivative of welfare to the medal score is given by:

(10) $\frac{\partial W}{\partial M_{i}}=\frac{p_{i}}{M_{i}^{\varepsilon}}$

From Eqs. (9) and (10) it can already be seen that the higher the population share, the higher the medal score must be. Further we know that for all $i$ :

(11) $\frac{\partial W}{\partial M_{i}}=\frac{\sum_{i=1}^{n} p_{i}}{M_{t}^{\varepsilon}}$

with

$M_{t}=$ total medal count;

$\sum_{i=1}^{n} p_{i} \equiv 1$

Solving (10) and (11) under the restriction that $\sum_{i} M_{i} \equiv M_{t} \equiv 301$ gives the optimal distribution $M_{i}^{*}=p_{i}^{1 / \varepsilon} / M_{t}($ see column 7 in Table 1$)$. As said, this welfare optimal

\footnotetext{
${ }^{17}$ Note that for $\varepsilon=1$, the welfare optimal distribution equals the default just distribution where medals are distributed according to population shares.
} 
distribution of medals abstracts from differences in production costs of OS between countries. Take the USA, the number one country with 35 gold medals. According to its population share, it would only qualify for 14 medals (see column 5 of Table 1). Now that the declining marginal utility is taken into account, this number further decreases to only 5 medals. Japan retains only 1 of its actual 16 gold medals. Even more dramatic are Germany, France, the UK and Italy. Their actual number of gold medals vary between 9 and 14, they qualify for at most 5 medals each according to population share and if the declining marginal utility is accounted for, they qualify for less than half a gold medal each. The winners in this exercise are India and China, qualifying for almost $90 \%$ of all gold medals, more than five times as large as their actual share. Finally, world welfare achieved under the optimal distribution is 9.85 , more than double the score of welfare under the actual distribution.

\section{The welfare optimal distribution with declining marginal utility of income}

So far, we have abstracted from the cost side of medal production. At the individual state level, the optimal number of medals is where the aggregate marginal social benefits equals the marginal social cost of medal production (see below), which is also known as the Samuelson condition for the optimal provision of public goods. At the supranational level, the favoured optimal distribution of the Olympic medal tally by a social planner (think of the IOC) is that distribution where the difference between the marginal social benefits and the marginal costs of medal production is equalized across countries. First we model the optimal number of medals for each country 
separately, under the restriction that the sum of all medals is fixed. In the model, we assume that because OS is a public good, the national governments of the participating countries at the Olympics are in some way or other in charge of producing the good in question, OS. Next, using the same model, the optimal distribution of medals of a social planner is derived.

Suppose governments face the following utility function of their citizens:

(13) $U_{i}=U_{i}\left(Y_{i}^{c}, M_{i}\right)$

with

$Y_{i}^{c}=$ per capita income.

Each country $i$ has a country-specific cost function $C_{i}\left(M_{i}, P_{i}, Y_{c}^{i}\right)$, depending on the number of medals to be produced, its population size and per capita income. The costs increase with the number of medals produced and with per capita income, but decrease with the size of the population. The government has to decide how much resources to devote to produce OS. Without state-sponsored promotion of topsport per capita income will be higher, at a level of $Y_{i}^{F}$, where the superscript $\mathrm{F}$ denotes full income. So the budget constraint is:

(14) $Y_{i}^{F}=Y_{i}^{c}+\frac{C_{i}\left(M_{i}, P_{i}, Y_{c}^{i}\right)}{P_{i}}$

As can be seen from the last term in Eq. (14), the costs of topsport promotion is a shared collective burden. The analysis is thus entirely analogous to the optimal 
provision of a public good. Substitution of the budget constraint (14) into the utility function (13) gives as maximization problem:

(15) $\operatorname{Max}_{M_{i}} U\left(Y_{i}^{F}-{ }^{C_{i}\left(M_{i}\right)} / P_{i}, M_{i}\right)$

which results in:

(16) $\frac{\partial U_{i}}{\partial M_{i}}=U_{Y_{i}^{c}} \frac{\partial Y_{i}^{c}}{\partial M_{i}}+U_{M_{i}}=0=-U_{Y_{i}^{c}} \frac{C_{M_{i}}}{P_{i}}+U_{M_{i}}$

Solving Eq. (16), taking into account that $\frac{\partial Y_{i}^{c}}{\partial M_{i}}=-\frac{C_{M_{i}}}{P_{i}}$ where $C_{M_{i}}$ is the marginal cost of medal production in country $i$, gives the well-known Samuelson condition:

(17) $P_{i} \frac{U_{M_{i}}}{U_{Y_{i}^{c}}}=C_{M_{i}}$

According to Eq. (17), the optimum for each country is where the sum of the marginal rates of substitution between the public good (medals) and the private good (per capita income) equals the marginal rate of transformation (or the marginal cost). The left hand side of Eq. (17) is the marginal social benefit (MSB) of a gold medal. The MSB is higher, the larger the population and the higher the per capita income - a higher per capita income corresponds with a lower marginal utility of per capita income $U_{Y_{i}^{c}}$, which enters as the denominator of the marginal utility of medals $U_{M_{i}}$ in Eq. (17). 
Basically, the optimization problem of national governments can be described as follows. The utility function has two arguments, per capita income and the medal score. The government can increase the medal score by expanding tax financed top sport facilities, which reduces per capita income. The cost function of producing OS has three arguments, the number of medals, per capita income and the population size. Only the latter has a negative relationship with per capita cost of OS: the larger the population, the larger the pool of talent available and the total cost of breeding calibre athletes can be spread over more people. The effects of two opposite forces must now be balanced. On the one hand governments of poor and populous nations should aim at a high medal score because the pool of talent is deep, the costs per capita are low and because per capita income is low (the latter can be taken as a good measure of the opportunity costs of fulltime athletes). On the other hand, they will invest little in top sport or OS because the marginal utility of per capita income is high. This last point can be made vivid by comparing The Netherlands and Cameroon. Both have an equal population size, but per capita income in the former is fifteen times as high as the latter. The welfare costs of the $€ 80$ million devoted to top sport in the present Olympic cycle of Beijing 2008 in order to achieve the Dutch ambition to belong to the top 10 countries is far lower than when Cameroon spends the same amount.

The resulting optimal distribution under both decreasing marginal utility of OS and per capita income is highly sensitive to both the parameter values and the specification of the cost and utility functions. To see how this works out, we have to make the cost and utility function a bit more explicit. In Eqs. (18)-(20) it is assumed that $(i)$ the utility function is additively separable; (ii) marginal utility of per capita income varies inversely with per capita income and (iii) marginal utility of medals is the same as under the Atkinson utility function (see also Eq. 5). For the cost function, 
it is assumed that $(i)$ a larger population decreases the cost of medal production, since a deeper pool of talent can be exploited - therefore, the supply side parameter $\gamma \leq 0$; (ii) however, because of the limited number of calibre athletes that each country can send to the Olympics (e.g. in team sports, each country can only have one entry), also $\gamma>-1$; (iii) the supply side parameter $\delta$ reflects decreasing, constant or increasing costs, depending on whether it is less, equal or greater than unity, as the number of medals goes up; (iv) finally, it can be assumed that the parameter $\alpha$ will be close to zero, as the number of calibre athletes will be a tiny fraction of the total population in a country.

(18) $U_{Y_{i}^{c}}=a / Y_{i}^{c}$

(19) $U_{M_{i}}=M_{i}^{-\varepsilon}$

(20) $C_{i}\left(M_{i}, P_{i}, Y_{c}^{i}\right)=c P_{i}^{\gamma}\left(Y_{i}^{c}\right)^{\alpha} M_{i}^{\delta} \Rightarrow C_{M_{i}}=\delta c P_{i}^{\gamma}\left(Y_{i}^{c}\right)^{\alpha} M_{i}^{\delta-1}$

Substituting (18)-(20) into (17) gives:

(21) $M_{i}^{*}=\left(\frac{\left(Y_{i}^{c}\right)^{1-\alpha} P_{i}^{1-\gamma}}{a c \delta}\right)^{1 /(\delta+\varepsilon-1)}$

Suppose, as Bernard and Busse (2004) argue, that population size is of no importance at all in producing Olympic talents, ${ }^{18}$ so $\gamma=0$, then the expression in between brackets boils down to the level of GDP per country - since GDP is the product of per

\footnotetext{
${ }^{18}$ The argument is that, as show by the DDR in the past, not talent is scarce, but the resources (material equipment, top sport knowledge, etc.) to raise talent potential to Olympic quality.
} 
capita income and population size and the parameter $\alpha$ will be close to zero ${ }^{19}$ - and the distribution of medals would be proportional to the distribution of GDP shares around the world as long as $\delta+\varepsilon=2 .{ }^{20}$ The results of the medals scores proportional to world GDP shares are presented in column 8 of Table 1 . Note that the declining marginal utility of per capita income works in the advantage of richer countries: in the trade-off between devoting more resources to medal production and higher per capita income, governments of rich countries will be more eager to devote resources to produce OS because the marginal utility of income is low compared to poor countries. The USA would go for more than 63 gold medals, almost twice its actual score and more than the medal scores of China and India together. Note that from all hypothetical distributions considered so far, this one is closest to the actual medal distribution. For instance, the medals scores of Germany, France, the UK and Italy (13, 9, 10 and 9) are pretty close to their actual medal scores $(14,11,10$ and 9). Notable exceptions, besides USA and India, are the countries that have historically an exceptional Olympic performance, like Cuba, Australia, Norway and all former socialist countries.

As column 8 of Table 1 shows, the medal distribution according to Eq. (21) is dramatically different from the hypothetical distributions according to population shares or declining marginal utility. The rich countries, in particular those with substantive populations like the USA and Japan, get high medal counts while poor countries with substantive populations like Indonesia, Brazil and Pakistan get low medal scores. Intuitively, this result can be explained as follows. Imagine two countries, one rich and one poor, all other things equal (so equal population size, e.g.

\footnotetext{
${ }^{19}$ I used the CIA factbook to obtain data for GDP per capita. Note that the cost of material equipment to sport can also be subsumed under the variable per capita income.

${ }^{20}$ E.g., $\varepsilon=0.5$ and $\delta=1.5$, or $\varepsilon=1$ and $\delta=1$. Because the parameters $a, c$ and $\delta$ are the same for all countries, the term $a c \delta$ does not play a role in Eq. (21).
} 
Japan and Nigeria). The rich country will spend more resources to produce OS because the marginal utility of income is much lower than in the poor country (see Eq. (17)). Using Eq. (21), it follows that

(22) $M_{r}^{*} / M_{p}^{*}=\left(Y_{r}^{c} / Y_{p}^{c}\right)^{(1-\alpha) /(\delta+\varepsilon-1)}$

with the subscripts $r$ and $p$ denoting rich and poor.

The results above refer to the case where each country selfishly strives to reach its optimal outcome, whatever the negative external effects imposed on other countries. Because of the zero sum game, a country succeeding in scoring one more medal imposes a negative externality on another country receiving one less medal. The social planner will try to minimize the welfare effects of these negative externalities. The social planner will try to balance the opposing effects of the inequality in per capita income between rich and poor countries and the effects resulting from differences in population size. Although the marginal cost of producing one more medal for the poor country will be lower because of its low per capita income, this effect is outweighed by its higher marginal utility of per capita income, if both are roughly of equal population size.

To arrive at the optimal result when countries coordinate their policies in such a way that overall an optimal outcome obtains, we can think what a social planner would do if it could allocate freely medals to countries, taking into account their utility and cost functions. The social planner would choose that distribution where $M S B_{i}-M S C_{i}$ is equalized, say to a constant value $q$, for all countries. Using Eq. (17), we get: 
(23) $P_{i} \frac{U_{M_{i}}}{U_{Y_{i}^{c}}}-C_{M_{i}}=q$

Substitution of Eqs. (18)-(20) and assuming for simplicity ${ }^{21}$ that $\delta=1$, gives:

(24) $M_{i}^{*}=\left(\frac{\left(Y_{i}^{c}\right)^{1-\alpha} P_{i}}{a\left(q+\delta c P_{i}^{\gamma}\right)}\right)^{1 / \varepsilon} \rightarrow a^{\prime}\left(\left(Y_{i}^{c}\right)^{1-\alpha} P_{i}^{1-\gamma}\right)^{1 / \varepsilon}$

The left hand side (LHS) of Eq. (24) can be approximated by the RHS if $a^{*} q$ is quantitatively of minor importance. Note that the RHS of Eq. (23) is, except for a constant term $a^{\prime}$, similar to Eq. (21) under the assumption that $\delta=1$. So, although Eq. (24) will result in a slightly different medal distribution than the one delivered by Eq. (21), the differences between both will probably be minor compared to the difference of these distributions and the ones according to population shares or declining marginal utility discussed in the previous sections. The social planner will take into account that in poor countries the welfare costs of promoting sport are far higher than in rich countries. Therefore, in maximizing world welfare, the social planner will largely (re)distribute in favour of the countries with high GDPs. ${ }^{22}$ The same mechanism applies in each country without the social planner, so by and large the distribution with a social planner will not be radically different from the one without the planner.

\footnotetext{
${ }^{21}$ Otherwise it will not be possible to arrive at an analytical solution.

${ }^{22}$ The social planner seeks the distribution where for each country the difference between MSB and MSC is equal. For poor and populous countries, she knows that the marginal costs of medal production are very low, because they have a large pool of talent to exploit. However, also the marginal benefits are modest, since GDP per capita is low, hence a high value for the marginal utility of per capita income which is the denominator of the MSB. The optimal point for these countries is therefore where both MSB and MSC are low. Compared to the poor countries, for the rich countries the social planner optimizes at a point where both the MSB and MSC are high.
} 


\section{The auction of entry tickets}

We have to acknowledge that the idea of a social planner redistributing medals while countries still have to incur the costs according to Eq. (14) and perceive to obtain benefits according to Eq. (13) is rather awkward. However, there is a body capable of regulating international sport affairs in a more equitable way. This body is the IOC, embodied with supranational authorities, sometimes even superseding policy preferences by individual NOCs. My point in introducing the IOC at this place is that it can devise a policy aimed at removing grinding disadvantages of some countries to obtain OS, financed by increasing the price of OS for rich and successful countries.

The policy is to auction the limited number of entries available at the Olympics. ${ }^{23}$ As noted in the introduction, about 11 thousand athletes participated in the last Games. Suppose the IOC distributed these 11 thousand entries according to population shares, so China would receive approximately 2266 entry rights, India 1859, USA 506 and Germany 143, and so on. India, with few calibre athletes, would be willing to sell a large share of their entry rights at the auction, whereas USA and Germany would be eager to buy additional entry rights. If the auction works well, a uniform equilibrium price will result. India, and other countries with a relatively low sport profile, would earn revenues, paid for by countries with a relatively high sport profile. Although for all countries the opportunity cost of sending athletes to the Olympics is increased by the equilibrium price of entries at the auction, the net effect

\footnotetext{
${ }^{23}$ Although the number of entries can be increased further, as well as the number of disciplines, there is a limit, beyond which too many qualification rounds have to be organized to arrive at the final, singling out the gold, silver and bronze medal winners. Therefore, the number of entries can be considered as a scarce good, which can be priced, bought and sold.
} 
is roughly a redistribution of money from countries with a ratio of medal share and population share higher than 1 towards countries with a ratio of medal share and population share lower than 1 . Recall the Lorenz curve drawn in section 2: the more a country is situated at the far left (like India and many other poor countries), the more it benefits from such a scheme, while the more a country is situated at the far right (like Norway, Australia and almost all other rich countries, as well as some former socialist countries), the more it is a net contributor to the scheme.

Of course, the IOC has to monitor that the earmarked revenues derived from the auction are really used to improve the sport infrastructure of the benefiting countries. If such a system works properly, the resulting medal tally would oscillate in between the two medal tallies we have seen in this paper: the one very biased towards the rich countries, like the actual medal tally and the medal tally preferred by a hypothetical social planner, and the other one biased towards the poor countries, like the medal tally proportional to population shares or equal contribution to welfare. The ensuing revenues allocated to sport facilities in poor countries will remove the major obstacle - money to buy sport equipment and topsport knowledge on the market - why these countries perform relatively under the mark at the Olympics. In the end, poor countries would be equally capable of breeding calibre athletes as rich countries, in which case few countries would have to buy or sell entries at the auction. The parade of athletes in the stadium at the opening ceremony would be a true reflection of the world population.

There are a few downsides to this proposal. First, poor countries might still prefer to cash in the revenues for selling part of their initially allocated entries at the auction, if the money could be spent on different purposes. However, since the money is earmarked, they can only spend it to promote sport. The only way the revenues of 
the auction distorts the allocation of resources at the national level is that these revenues partly or fully replace the national sport budget. In any case, since these countries are poor, in principle at least the 'deadweight' costs will be minor, if not negative (this would be the case if because of the inflow of auction revenues the national sport budget money is redirected to other, more beneficial programs for the country)

Second, and more serious, the scheme could have the result that not the best athletes worldwide would enter the pitch at the Olympics. The present qualification regime, with pre-Olympic tournaments in which qualification tickets (entries) to the Olympics can be won, is exactly geared towards mobilizing a prefixed number of the very best to the Games. It might be expected that rich countries, since marginal utility of per capita income is much lower, would be more eager to take the bet, buy an additional entry at the auction, and send an athlete with only a small medal-winning chance. Thus, rich countries would always keep their competitive edge simply because they are rich. They can easily afford the costs of buying additional entry tickets, even if their athletes are of lower rank than athletes from poor countries for whom no entry ticket is available, despite passing the qualification. The poor countries would have the incentive to limit the number of athletes as far as possible, only sending the ones with a reasonable high chance of winning a medal. True, but this would be a temporary phenomenon, because sooner or later the sports investments, financed by the revenues of the auction, will bear fruit. Moreover, since many Olympic disciplines are capital intensive, there is already a huge built-in bias in favour of the predominantly rich countries which can afford the necessary expenditures and infrastructure to nourish these sports (think of equestrian sports, yachting, sailing). Cross-subsidization might counteract this bias. 
Third, one may be inclined to think that OS is a good that is not for sale. This argument would have a bite if medals, not entries, would be for sale. An entry is no guarantee for a medal, only a license to compete for the medal. My rough guess is that even the poorest country in the world will send athletes with a real chance to win a medal to the Games, even if they have to forego the revenues of selling the entry ticket at the auction.

To conclude, it might be feasible to combine the best of both systems. The present pre-Olympic qualification tournament system can be made less strict, with the result that more, say twice as much, qualification tickets are issued than entries available at the final Olympics. If tradable entry tickets are allocated proportional to population shares, rich countries with a disproportional high ratio of qualification tickets and entry tickets can only effectuate the former by buying additional entry tickets from the countries with a disproportional low ratio of qualification and entry tickets. This system might help to keep the Olympic Games truly a feast of brotherhood of (wo)mankind around the world, always leaving open the possibility that in the distant future the Games are really global, indiscriminate to sex, race, religion and income. ${ }^{24}$

\section{References}

Atkinson, A.B. (1983), The Economics of Inequality, Oxford, OUP.

\footnotetext{
${ }^{24}$ Suppose, for convenience, that by adopting this system in the end all world citizens have access to the same facilities to breed their sport talents. The medal tally that results will reflect which countries have comparative advantages or strong preferences to excel in particular sports, e.g. Kenya in distance running and Australia in swimming (my rough guess is that we hardly know which countries have comparative advantages in particular sports - maybe Tanzanians are great surfers, see Tcha and Pershin (2003) for some clues). This distribution will be different from the one which maximizes world welfare; at best it strikes some sort of balance between the welfare optimal and the default just distribution. Still, it has the merit that it reveals who is really the best in its discipline worldwide, whereas in the present state the distribution is heavily biased towards the rich countries and countries with a strong political preference for OS.
} 
Baimbridge, M. (1998), Outcome Uncertainty in Sporting Competition: The Olympic Games 1896-1996, Applied Economics Letters, 5(3): 161-64.

Bian, X. (2005), Predicting Olympic Medal Counts: the Effects of Economic Development on Olympic Performance, Park Place Economist, Vol. XIII, 3744.

Bernard, A.B. and M. R. Busse (2004), Who Wins the Olympic Games: Economic Resources and Medal Totals, Review of Economics and Statistics, 86(1): 41317.

Hoffmann, R., L. C. Ging and B. Ramasamy (2002), Public Policy and Olympic Success, Applied Economics Letters, 9(8): 545-48.

Hoffmann, R., L. C. Ging and B. Ramasamy (2004), Olympic Success and ASEAN Countries: Economic Analysis and Policy Implications, Journal of Sports Economics, 5(3): 262-76.

Johnson, D.K.N. and A. Ali (2004), A Tale of Two Seasons: Participation and Medal Counts at the Summer and Winter Olympic Games, Social Science Quarterly, 85(4): 974-93.

Matros, A. and S.D. Namoro (2004), Economic Incentives of the Olympic Games, Working paper University of Pittsburgh.

Moosa, I.A. and L. Smith (2004), Economic Development Indicators as Determinants of Medal Winning at the Sydney Olympics: An Extreme Bounds Analysis, Australian Economic Papers, 43(3): 288-301.

Tcha, M. (2004), The Color of Medals: An Economic Analysis of the Eastern and Western Blocs' Performance in the Olympics, Journal of Sports Economics, 5(4): 311-28.

Tcha, M. and V. Pershin (2003), Reconsidering Performance at the Summer Olympics and Revealed Comparative Advantage, Journal of Sports Economics, 4(3): 216-39. 